\title{
Glycerol impregnation of a formaldehyde fixed Bump-head Sunfish Mola alexandrini
}

\author{
Ian D. MacLeod', Glenn I. Moore ${ }^{2,3, *}$ and Salvador Gomez \\ ${ }^{1}$ Western Australian Maritime Museum, Victoria Quay, Fremantle, Western Australia 6160, Australia. \\ 2 Department of Aquatic Zoology, Western Australian Museum, 49 Kew Street, Welshpool, \\ Western Australia 6106, Australia. \\ ${ }^{3}$ School of Biological Sciences, University of Western Australia, Nedlands, Western Australia 6907, \\ Australia. \\ * Corresponding author: glenn.moore@museum.wa.gov.au
}

\begin{abstract}
A Bump-head Sunfish Mola alexandrini washed ashore in south-western Australia and was provided to the Western Australian Museum for exhibition. However, using traditional museum practices, such a large specimen would require a large volume of ethanol, which provides an unacceptable public risk in an exhibition space. The low risk glycerol was chosen as a storage medium. The specimen was initially fixed in a $10 \mathrm{v} / \mathrm{v} \%$ formaldehyde solution and soaked in fresh water to remove residual formalin before commencing glycerol impregnation. Over a period of several years, glycerol impregnation was achieved by step-wise increases at 30\%, 40\%, 49\% and $59 \%$ glycerol. Biodegradation was inhibited with Kathon CG biocide. The impregnation process was monitored with a digital densitometer, which confirmed the process was controlled by diffusion through the spaces surrounding denticles and the concentration of the impregnating solution and was dependent on the logarithm of time. This method is a viable and safe alternative to the storage of natural history specimens when ethanol is not an option, and delivers measurable improvements to the colour and flexibility of specimens.
\end{abstract}

KEYWORDS: exhibition, conservation, preservative, museum, flexibility

\section{INTRODUCTION}

In August 2010, a Bump-head Sunfish Mola alexandrini (Ranzani, 1839) (WAM P.33481-001; $1,380 \mathrm{~mm} \mathrm{TL} ; 148 \mathrm{~kg}$; Figure 1) was found dead on a beach near Augusta, south-western Australia ( $\left.34^{\circ} 19^{\prime} 53^{\prime \prime} \mathrm{S}, 115^{\circ} 10^{\prime} 14^{\prime \prime E}\right)$. Identification was made on the basis of general body shape, 12 ossicles in the clavus and denticle structure (Hutchins 2001; Nyegaard et al. 2018).

The sunfish was identified as a potential key exhibition item for indoor display at the Western Australian Museum. The traditional museum practice for fishes is formalin fixation followed by storage in $70 \%$ ethanol. However such a large specimen would require more than 1,500 litres of ethanol, which provides an unacceptable public risk in an exhibition space with regards to fire, volatile fumes or skin contact in the event of deliberate or accidental damage to the display case, as well as the need for more sophisticated air handling and fire suppression systems. Thus, a nonvolatile storage fluid was sought. Previous experience with treating a 5.3 metre Megamouth Shark indicated that aqueous solutions of glycerol were likely to provide a suitable medium (MacLeod 2015).

\section{RATIONALE FOR CHOOSING A STEPWISE GLYCEROL IMPREGNATION}

The concept of using stepwise addition of glycerol to formaldehyde-fixed natural science specimens was inspired by a visit to the Anatomical Museum of the Leiden University Medical Centre in The Netherlands where 100-year-old glycerol impregnated specimens of human organs appeared to be in excellent condition. The presence of three hydroxyl groups in glycerol $(1,2,3$ trihydroxy propane) makes it an ideal organic reagent with which to impregnate specimens because the glycerol will be strongly absorbed by the structural cellular components through hydrogen bonding, thereby preventing cellular collapse associated with dehydration. The way in which density relates to concentration is linear (Wolf et al. 1974) and so monitoring the solution density allows the progress of the impregnation to be recorded. The basis for using aqueous glycerol as an exhibition medium for preserved fish lies in the high flash point of the final solution. Whereas a $70 \mathrm{v} / \mathrm{v} \%$ (hereafter $70 \%$ ) ethanol solution has a flash point of $16.6^{\circ} \mathrm{C}$, a glycerol concentration of $97.5 \%$ is required before it will flash at $190^{\circ} \mathrm{C}$ (Glycerine Producers 
Association 1963). Under the Australian Poisons Standards (Australian Government 2017) glycerol is classified as a Schedule 1 substance which has no restrictions on its use, so its handling presents no Occupational Health and Safety (OHS) issues.

\section{MODELLING THE ABSORPTION OF GLYCEROL IN SHARKS}

The suitability of using formalin-fixed tissue natural science specimens stored in aqueous glycerol solutions was tested with two small sharks; a Scalloped Hammerhead Sphyrna lewini and a Grey Reef Shark Carcharhinus amblyrhynchos (MacLeod and van Dam 2011), which demonstrated that impregnation with aqueous solutions of glycerol is an effective method for replacing ethanol as the storage medium. The methodology was scaled up to treat a 5.3 metre Megamouth Shark Megachasma pelagios which had been previously stored in $70 \%$ ethanol (Human et al. 2012; MacLeod 2015).

Understanding the mechanism of absorption of glycerol into sharks and other marine specimens can lead to an improvement in collection management practices through optimising the rate of glycerol impregnation. The model for glycerol absorption, which gives logarithmic time dependence, is based on the absorption of gases onto a reactive surface. For the liquid phase reactions, the concentration of gases is replaced by the concentration of glycerol and this variable controls the rate of uptake of the stabilising chemical (Denbigh 1964). The areas of the shark skin that are free of denticles are reactive, which is akin to the gas absorption process on physically reactive surfaces. The fraction $\theta$ of the covered surface is given by the ratio of $m / M$ where $m$ is the total number of molecules absorbed and $M$ is the number of sites. Part of the driving force for the free energy change associated with the absorption of glycerol into the shark tissue is the lower energy that the glycerol molecules have when they are hydrogen bonded with the proteins in the shark musculature. The free energy of absorption is defined by Equation 1 (Graham 1953),

$$
\mu-\mu^{0}=\Delta \mathrm{H}-\mathrm{T}\left(\mathrm{S}-\mathrm{S}^{0}\right)+2.303 \mathrm{RT} \log \{\theta / 1-\theta\}
$$

where $\Delta \mathrm{H}$ is the heat given off through the absorption of glycerol and $\mathrm{S}$ is the entropy per mole of the absorbed glycerol. The superscript ${ }^{0}$ for entropy and free energy $\mu$ refer to a standard $1 \mathrm{M}$ glycerol solution. Equation 1 shows that the energy driving absorption is dependent on the logarithm of the fraction of the surface responding to the absorption process. It is therefore not surprising that the kinetics of glycerol absorption and desorption of formaldehyde from the Megamouth Shark followed linear trends with the logarithm of treatment time (MacLeod 2015).
The three previous successful shark impregnation experiments gave us confidence that the direct impregnation of a formalin-fixed fish with glycerol carried a low risk to the specimen. Serial additions of glycerol to the shark treatment solutions, which began at $30 \%$, brought about significant improvements in flexibility of all fins and the jaw as well as reducing the alcohol induced shrinkage lines (MacLeod and van Dam 2011; MacLeod 2015).

\section{GLYCEROL IMPREGNATION OF THE SUNFISH}

Since the skin surface of sunfish is similar to sharks, in that they are covered with denticles, we expected that the specimen might follow similar kinetics for the impregnation treatment with glycerol. We also anticipated similar improvements in flexibility and colour of the sunfish specimen. Therefore, the same step-wise addition of glycerol used for the Megamouth Shark was applied to the sunfish but it was stopped at a slightly lower level (59 compared with 65\% glycerol) because the balance between the rigidity of the specimen and the ability to pump the solution around the exhibition tank had been reached. Given that immersion in alcohol is known to cause changes to large specimens (Human et al. 2012), the sunfish was moved directly from the formalin fixative (following washing) to glycerol impregnation, without an ethanol step.

\section{METHODS}

The sunfish specimen was frozen for transport and then fixed in a small PVC lined commercial wading pool (1,200 litres capacity) using a buffered 10\% formaldehyde solution. Three litres of the fomaldehyde solution was injected haphazardly into the dorsal and lateral musculature and the gut cavity. The specimen was immersed in formaldehyde solution and the whole assembly was encapsulated in high density polyethylene 'builders black plastic' (1.5 mm thick). Formalin concentration was monitored and adjusted as required. This work was done outside the building under the cover of an awning under ambient temperature conditions. During the impregnation, downdraft full face respirators with formaldehyde filters and other personal protective equipment was worn. After one year in formaldehyde, a small core (4 $\mathrm{mm}$ diameter) was taken from beneath the left pectoral fin to confirm that the specimen was properly fixed prior to the glycerol solution treatment. Histological examination confirmed that formaldehyde fixing had been effected.

Excess formaldehyde was removed by soaking the sunfish for four weeks in fresh water with several water changes. The extended washing period was based on previous studies that demonstrated that the release of formaldehyde from sharks followed logarithmic kinetics (MacLeod 2008, 2015) and was needed to ensure that staff working in and around the specimen were not 
exposed to an OHS risk associated with the toxicity of formaldehyde (Kim et al. 2011).

The sunfish was placed onto a supporting cradle comprising two high density polyethylene (HDPE) pallets that had been fastened together (Figure 1). The sunfish, on its cradle, was lifted into a custom made high density PVC 5,000 litre tank, which was dark and airtight when sealed. The tank lid was sealed with a rubber gasket and held in position with stainless steel bolts around the perimeter. The support cradle was weighed with and without the sunfish on a one tonne capacity digital weighing scale to determine initial weight of the fish $(148 \mathrm{~kg})$. The tank was filled with c. 2,000 litres of $30 \%$ glycerol that was reused from a previous treatment process (Megamouth Shark; MacLeod 2015) following fine filtering $(<10 \mu \mathrm{m})$. Owing to the lower body density of the sunfish compared with the impregnating solution of $30 \%$ glycerol (1.0853 g/ $\mathrm{cm}^{3}$ ) a restraining band of open weave polyethylene shadecloth was placed across the specimen and clean concrete blocks were used to weigh the shadecloth and cradle down to keep the specimen submerged.

The volume of the sunfish specimen was determined by measuring displacement of the $30 \%$ glycerol solution after correcting for the volumes of the cradle and concrete blocks. Geometric surface area was calculated from calibrated photographs. In order to understand the nature of the skin surface, the biopsy was washed in aqueous ethanol, examined under SEM and subjected to elemental analysis (SEM EDAX: Energy Dispersive Analysis of X-rays) at the CSIRO microscopy unit at the Australian Resources Research Centre, Kensington, Western Australia. For both the sunfish skin sample and a sample of Megamouth Shark skin, the free surface area available to glycerol was calculated using Adobe Photoshop, after converting the denticles to white and the background to black.

\section{CONTROL OF MICROBIOLOGICAL ACTIVITY}

Since most of the glycerol solutions were reused from the Megamouth Shark treatment process (MacLeod 2015) there was residual biocide in the solution which, combined with slow release of a small amount of residual formaldehyde from the sunfish, meant that the $30 \%$ solution did not exhibit any issues of microbiological decay. However, as the concentration of glycerol was increased, some signs of biological activity were noted, in the form of tiny suspended microbial mats, so a circulation pump and inline filter

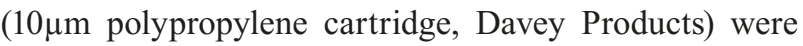
subsequently installed and operated for one hour per day. The biocide Kathon CG (methylchloroisothiazolinone in conjunction with the parent methylisothiazolinone), was used to prevent microbiological decay of the specimen and the glycerol solutions. The average level of biocide dosage was 25 ppm (Graves 2004) and no further microbial activity occurred.

\section{MONITORING THE IMPREGNATION PROGRESS}

The treatment of the sunfish was monitored by regular measurement of the solution density (to four decimal places) and temperature with a digital densitometer (Anton Paar Model DMA 35N). Density was standardised to a set temperature of $20^{\circ} \mathrm{C}$, since the density of aqueous glycerol solutions typically varies by $\pm 0.0003 \mathrm{~g} / \mathrm{cm}^{-3} .{ }^{\circ} \mathrm{C}^{-1}$. The treatment area was not climate controlled, and the range of solution temperatures during the impregnation period ranged from $21.9 \pm 1.1^{\circ} \mathrm{C}$ (mean winter) to $24.6 \pm 1.6^{\circ} \mathrm{C}$ (mean summer) with a mean of $24.0 \pm 1.8^{\circ} \mathrm{C}$ across the four year treatment program. During the initial $30 \%$ glycerol stage of impregnation there was no pump installed in the tank (see above) and the glycerol solution was uncirculated, so density measurements were taken at various points around the specimen, allowing us to assess differential absorption rates by different parts of the body. The installation of the pump resulted in a more uniform solution environment around the specimen, as well as removing fine sediments and microbes.

Once the glycerol density had plateaued, equilibration was deemed to have occurred and the glycerol solution was pumped out and replaced with an approximately equal volume of more concentrated solution. The stepwise increases in concentration were: $30 \%, 40 \%$, $49 \%$ and $59 \%$. These incremental steps were used largely as a cost saving measure by reusing solutions
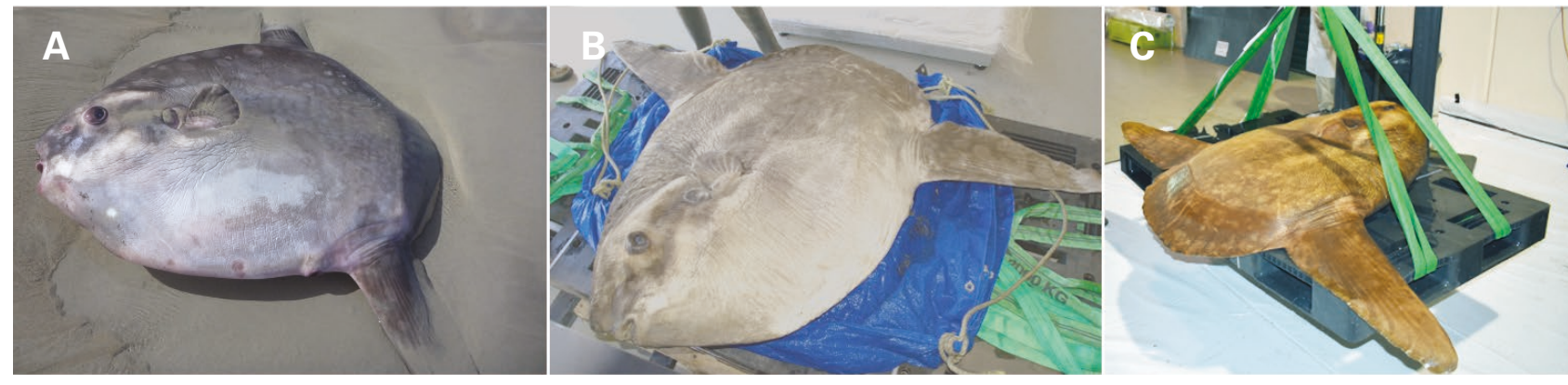


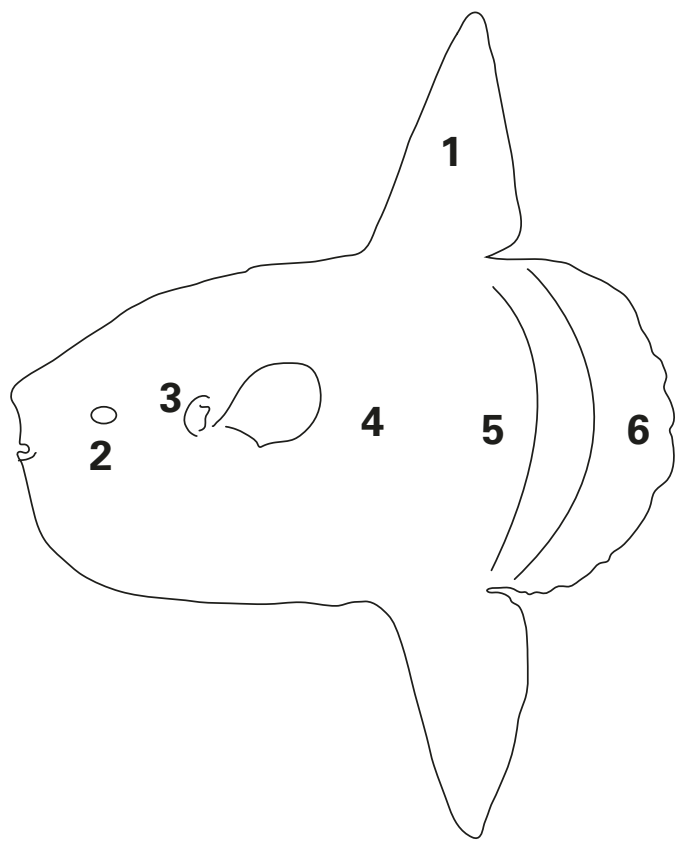

FIGURE 2 Location of measurement points for the colour measurements on Bumphead Sunfish Mola alexandrini using a chromameter (drawing after Whitley 1933).

from the Megamouth Shark treatment program. The final concentration was achieved by decanting 300 litres of $49 \%$ solution and adding 400 litres of $98 \%$ glycerol to increase the glycerol concentration to $59 \%$. While a higher final solution concentration might provide a lower over-solution humidity to prevent fungal growth, $59 \%$ was used due to cost considerations, the inability of the pump and the filtration system to cope with the increased viscosity and was further counteracted by the efficacy of the biocide to prevent fungal growth. At the end of the treatment the sunfish was raised on its support structure and allowed to drain before being re-weighed. Since the treatment was finished the sunfish has been in storage in a darkened tank awaiting installation as an exhibition specimen.

\section{COLOUR CHANGES DURING GLYCEROL TREATMENT OF SHARKS}

It was previously determined that the apparent restoration of the natural colour of small sharks during glycerol treatment was not due to a chemical reaction but rather, it was a change in the surface properties of the skin that altered the reflectance of light (MacLeod 2015). It is likely that the dehydration of the shark skin by long term storage in $70 \%$ ethanol was overcome by the aqueous glycerol which fully wetted the surface and achieved colour saturation, thereby apparently 'reversing' the alcohol induced colour changes (MacLeod 2015). Even the sun-bleached Megamouth Shark showed a significant improvement in its colour during glycerol treatment (MacLeod 2015). Since the direct glycerol impregnation of the sunfish was being tested for the first time, we gauged the impact of glycerol impregnation on colour by taking colour measurements at six points across the body using standard CIELAB colour measurements on a Minolta Chromameter (MacLeod and Gilroy 1989). The measurement points were distributed over the light and dark areas of the specimen and across a range of surfaces (Figure 2). The chromameter uses an internal xenon tube as a constant light source, conducts three readings and returns the average value in the $L^{*} a * b *$ format.

The $\mathrm{L}^{*} \mathrm{a} * \mathrm{~b} *$ system uses three dimensional coordinates for every known colour: positive $L^{*}$ values reflect whiteness and negative $\mathrm{L}^{*}$ values are for shades of black. Positive $a^{*}$ values are in the red spectrum and negative $a^{*}$ values are green, while positive $b^{*}$ values are for yellow and negative values denote shades of blue. Colour change is measured according to the distance in the three dimensions between colour points and is defined by the formula given in Equation 2,

$$
\Delta \mathrm{E}=\left\{\left(\mathrm{L}_{1}^{*}-\mathrm{L}_{2}{ }_{2}\right)^{2}+\left(\mathrm{a}^{*}{ }_{1}-\mathrm{a}_{2}{ }_{2}\right)^{2}+\left(\mathrm{b}^{*}{ }_{1}-\mathrm{b}_{2}\right)^{2}\right\}^{1 / 2}
$$

\section{RESULTS}

The sunfish specimen had an estimated geometric surface area of $4.4 \mathrm{~m}^{2}$ and a displacement volume of 235 litres with an apparent density of $0.58 \mathrm{~g} / \mathrm{cm}^{-3}$ (based on a solution density of $1.0853 \mathrm{~g} / \mathrm{cm}^{-3}$ for the $30 \%$ solution). SEM imaging showed that each denticle of the sunfish skin was surrounded by a zig-zag structure of the mineral growth that formed the surface of the skin providing 38\% free area where glycerol can penetrate into the fish's tissues, including the perforations in the denticles (Figure 3). In contrast, SEM of the Megamouth Shark skin showed that the denticles are like mesa formations sitting above the plain of the surface with a free area of $58 \%$ (Figure 3). The elemental analyses of

TABLE 1 SEM semi-quantitative analysis of skin and denticle sample from a Bump-head Sunfish Mola alexandrini.

\begin{tabular}{ll} 
Element & $\begin{array}{l}\text { Normalised } \\
\text { atomic \% }\end{array}$ \\
\hline Oxygen & 61.3 \\
Calcium & 23.2 \\
Phosphorus & 13.4 \\
Silicon & 0.9 \\
Aluminium & 0.6 \\
Sulphur & 0.4 \\
Zinc & 0.3 \\
\hline
\end{tabular}



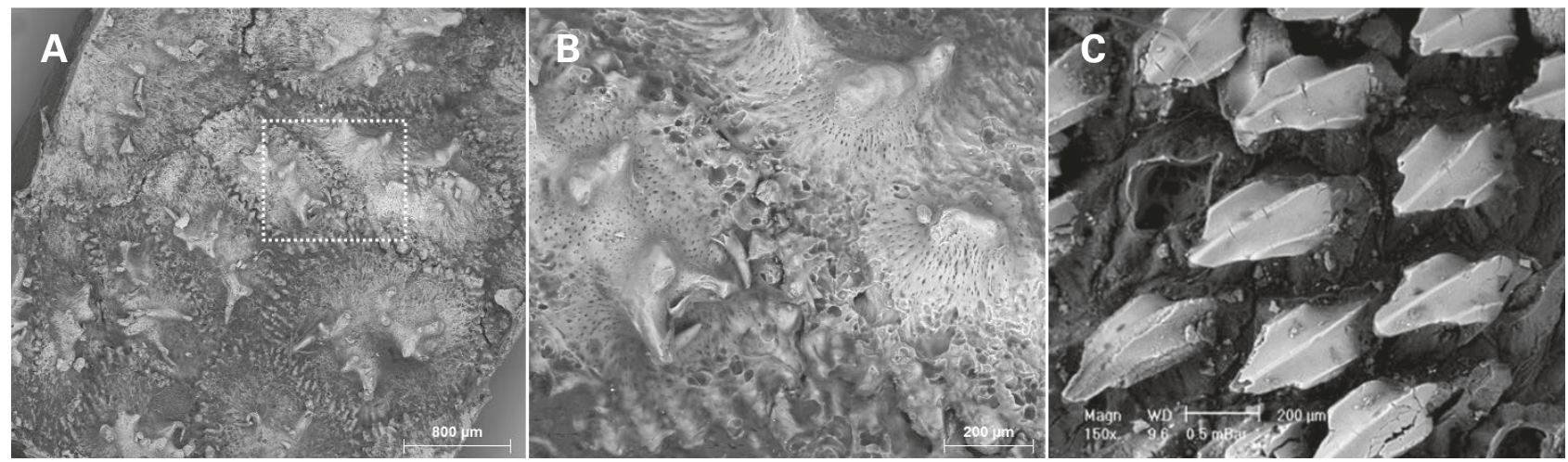

FIGURE 3

Comparison of scanning electron microscope (SEM) images of dermal denticles. A) Bump-head Sunfish Mola alexandrini (magnification 55x); B) detail of box in figure a. (magnification 180x); C) Megamouth Shark Megachasma pelagios (magnification 150x).

the denticles on the sunfish confirmed that they largely consisted of calcium hydroxy apatite, $\mathrm{Ca}_{10}\left(\mathrm{PO}_{4}\right)_{6}(\mathrm{OH})_{2}$, after correction for entrained fine sand grains (Table 1). The small amounts of aluminium, sulphur and zinc on the denticle surface is consistent with surface contamination, with some clays and other minerals in the very fine sand particles trapped under the fin where the skin sample was taken.

\section{DIFFERENTIAL IMPREGNATION IN STATIC GLYCEROL SOLUTION}

During the $30 \%$ glycerol stage (i.e. pre-pump, static) there was an approximately $23 \%$ higher rate of absorption of glycerol from around the clavus (tail) than over the rest of the body (Table 2). The difference is probably due to the reduced number of denticles between the clavus and the body of the fish to permit free movement in association with the anal and dorsal fins from which it is derived (Fraser-Brunner 1951; Pope et al. 2010). Regression analysis confirms that they both have the same starting point or intercept value of the original $30 \%$ solution. Once the pump was installed these differences disappeared as the stirring ensured a homogeneous solution density.

\section{EFFECTS OF CHANGING GLYCEROL CONCENTRATION}

With the exception of the $30 \%$ glycerol step, each stage of impregnation comprised an initial rapid rate followed by a slower rate (Figure 4). The first stage of glycerol impregnation $(30 \%)$ reached a plateau level after 161 days, although it was maintained in this state for almost a year (353 days) owing to other operational duties. Routine monitoring during this long stasis ensured that the specimen was intact and that there was no biodegradation. When the tank was opened for changing the solution concentration, the mobility of the fins was checked and all showed significant mobility improvements, even at the early stages of impregnation.

During the first 84 days in the $40 \%$ solution, the density fell at an initial rapid rate of $-0.084 \mathrm{~g} / \mathrm{cm}^{3} / \mathrm{log}$ time $(t)$, which fell away to a steady $-0.015 \mathrm{~g} / \mathrm{cm}^{3} / \mathrm{log}$ $t$, (Table 3 and Figure 4) for another 226 days. Thus this second step in the impregnation took 310 days. During the $49 \%$ glycerol impregnation the rapid drop in density occurred at a rate of $-0.32 \mathrm{~g} / \mathrm{cm}^{3} / \log t$ for only 8 days. This was followed by a slower absorption rate $\left(-0.029 \mathrm{~g} / \mathrm{cm}^{3} / \log t\right)$ with densities that oscillated during times of increased solution temperature from either pump-generated heat or increased ambient temperatures. The movement of glycerol in and out of the specimen appears to be quite sensitive to

TABLE 2 Differential absorption rates of glycerol in clavus and body of a Bump-head Sunfish Mola alexandrini for non-circulated solution of $30 \mathrm{v} / \mathrm{v} \%$ glycerol. Megamouth Shark Megachasma pelagios data from MacLeod (2015). * The lower density for the intercept for the Megamouth Shark is due to outward diffusion of ethanol based preservative which had lowered the glycerol to $28.6 \%$.

\begin{tabular}{llll} 
Region & $\begin{array}{l}\text { Density decrease } \\
\left(\mathrm{g} / \mathrm{cm}^{3} / \log \text { hours }\right)\end{array}$ & $\begin{array}{l}\text { Intercept density } \\
\left(\mathrm{g} / \mathrm{cm}^{-3}\right)\end{array}$ & $\mathrm{R}^{2}$ \\
\hline Clavus & $-0.0027 \pm 0.0002$ & $1.0925 \pm 0.0006$ & 0.9785 \\
Body & $-0.0022 \pm 0.0001$ & $1.0924 \pm 0.0019$ & 0.9945 \\
Megamouth & $-0.0307 \pm 0.0001$ & $1.0885^{*} \pm 0.0008$ & 0.9917 \\
\hline
\end{tabular}




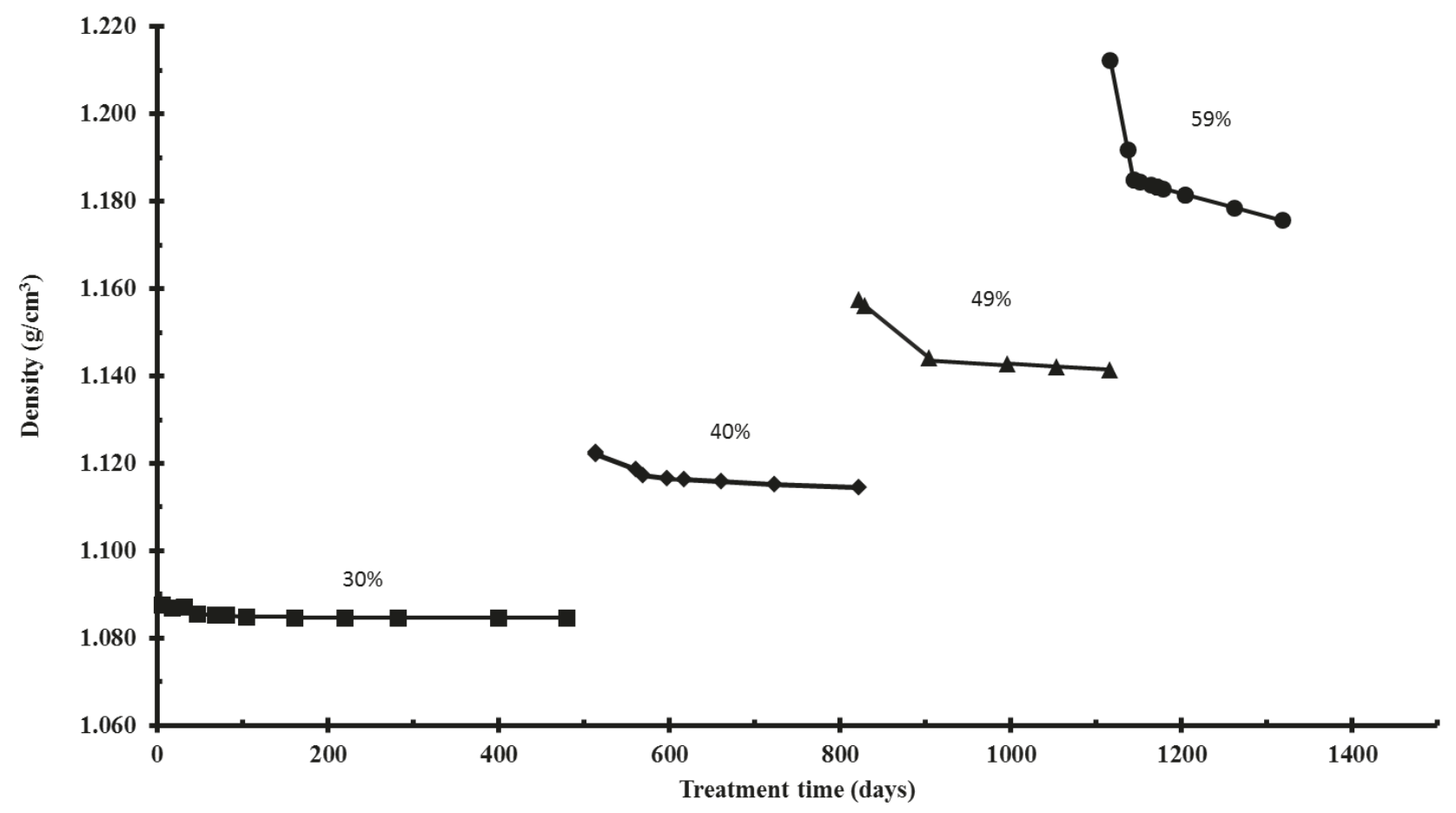

FIGURE 4 Change in density of glycerol solution during the step-wise impregnation of a Bump-head Sunfish Mola alexandrini in 30\%,40\%, 49\% and 59\% glycerol.

TABLE 3 Rates of fall in density of glycerol solutions during impregnation treatment of a Bump-head Sunfish Mola alexandrini in 30\%, 40\%, 49\% and 59\% glycerol.

\section{Initial 'Rapid' Rate}

Slope $\left(\mathrm{g} / \mathrm{cm}^{3} / \log\right.$ time $)$

$-0.0022$

$-0.0840$

$-0.3200$

$-2.6100$

Slope error

$\pm 0.0006$

$\pm 0.0480$

n.a.

$\pm 0.4100$

$\mathrm{R}^{2}$

0.9945

0.7530

n.a.

0.9529

Intercept $\left(\mathrm{g} / \mathrm{cm}^{3}\right)$

1.0924

1.4700

2.5100

12.7500

Intercept error

$\pm 0.0019$

$\pm 0.2000$

n.a.

$\pm 1.8100$

Secondary 'Slow' Rate

Slope $\left(\mathrm{g} / \mathrm{cm}^{3} / \log\right.$ time$)$

Slope error

$\mathrm{R}^{2}$

Intercept $\left(\mathrm{g} / \mathrm{cm}^{3}\right)$

Intercept error

\section{$-0.0022$}

$\pm 0.0006$

0.9945

1.0924

$\pm 0.0019$
$-0.0146$

$\pm 0.0009$

0.9418

1.1808

$\pm 0.0390$
$-0.0294$

$-0.151$

0.0076

$\pm 0.0550$

0.9376

0.7906

1.2800

1.8400

$\pm 0.2400$ 
temperature since the corrected density fell at twice the rate $\left(-0.0022 \mathrm{~g} / \mathrm{cm}^{3}\right)$ between 25.5 and $27.5^{\circ} \mathrm{C}$ compared with the lower temperature range $23.5-24.1^{\circ} \mathrm{C}(-0.0010$ $\left.\mathrm{g} / \mathrm{cm}^{3}\right)$. This third stage of the treatment at $49 \%$ took another 210 days (Table 3). For the final 59\% glycerol impregnation stage, there was an initial rapid uptake of the glycerol with the density falling at a rate of $-2.61 \mathrm{~g} /$ $\mathrm{cm}^{3} / \log t$ for an initial 27 days followed by at least 60 days of further equilibration at a rate of $-0.15 \mathrm{~g} / \mathrm{cm}^{3} /$ $\log t$ (Table 3; Figure 4). Linear regression analysis of the logarithm of the rate of rapid density change (Table 3) showed a linear increase with the glycerol concentration, as shown in Equation 3,

$$
\log \text { Rapid }_{\text {density fall }}=-5.45+0.101 \%_{\text {glycer }}
$$

The regression analysis had an $\mathrm{R}^{2}$ of 0.9674 which equates to errors of $11 \%$ in the intercept and $13 \%$ in the slope. Analysis of the slower absorption rate (Table 3) showed the same dependence on glycerol concentration (same slope), but a different intercept value (Equation 4),

$$
\log \text { Slow }_{\text {density fall }}=-5.76+0.102 \%_{\text {gl }}
$$

The four data points have an $\mathrm{R}^{2}$ of 0.9809 with a standard error of \pm 0.46 or $8 \%$ in the intercept and an error of \pm 0.010 of $10 \%$ in the slope of Equation 3 (Figure 5).

\section{COLOUR AND WEIGHT CHANGE}

Colour changes in the specimen took place gradually as the glycerol diffused into the sunfish and the surface became fully wetted and colour saturated (Table 4). The mean colour difference, $\Delta \mathrm{E}_{\text {mean }}$ was $4.2 \pm 1.8$ and most of the measurement points became darker, with the exception of measurement point 3 (midoperculum) which increased in brightness but the $a^{*}$ value was constant and $b^{*}$ value decreased, making it appear less yellow. Overall, the visual effect of the glycerol treatment was towards a much browner hue. Photographs of the sunfish showed a greater contrast between the light coloured spots and the darker surrounding skin (Figure 1). A standard measure of colour change is noted as a 'just noticeable fade' and has a $\Delta \mathrm{E}$ of 0.32 (Ford 2011) and all the colour measurements on the sunfish show that the specimen has

TABLE 4 Colour measurements on a Bump-head Sunfish Mola alexandrini before and after glycerol treatment based on $L^{*} a^{*} b^{*}$ system (see Methods). Difference is final minus initial measurement. See Figure 2 for

\begin{tabular}{|c|c|c|c|c|c|}
\hline Measurement point & measurement & $L^{*}$ & $a^{*}$ & $b^{*}$ & $\Delta \mathrm{E}$ \\
\hline \multirow{3}{*}{1} & initial & 34.2 & 4.9 & 10.4 & \multirow{5}{*}{7.4} \\
\hline & final & 27.3 & 3.5 & 8.3 & \\
\hline & difference & -6.9 & -1.4 & -2.2 & \\
\hline \multirow{3}{*}{2} & initial & 31.4 & 7.5 & 13.2 & \\
\hline & final & 31.8 & 6.6 & 15.6 & \\
\hline & difference & +0.4 & -0.9 & +2.4 & \multirow[t]{2}{*}{2.6} \\
\hline \multirow{3}{*}{3} & initial & 22.4 & 4.5 & 6.5 & \\
\hline & final & 25.2 & 4.7 & 5.2 & \multirow[b]{2}{*}{3.1} \\
\hline & difference & +2.8 & +0.1 & -1.3 & \\
\hline \multirow{3}{*}{4} & initial & 36.6 & 6.2 & 10.9 & \multirow[b]{3}{*}{5.5} \\
\hline & final & 31.5 & 4.3 & 10.3 & \\
\hline & difference & -5.2 & -1.9 & -0.6 & \\
\hline \multirow{3}{*}{5} & initial & 35.5 & 5.4 & 10.5 & \multirow{5}{*}{3.0} \\
\hline & final & 33.1 & 4.2 & 11.7 & \\
\hline & difference & -2.4 & -1.2 & +1.3 & \\
\hline \multirow{3}{*}{6} & initial & 31.8 & 5.6 & 9.4 & \\
\hline & final & 30.0 & 2.8 & 7.4 & \\
\hline & difference & -1.8 & -2.9 & -2.0 & 3.9 \\
\hline
\end{tabular}
location of measurement points. 


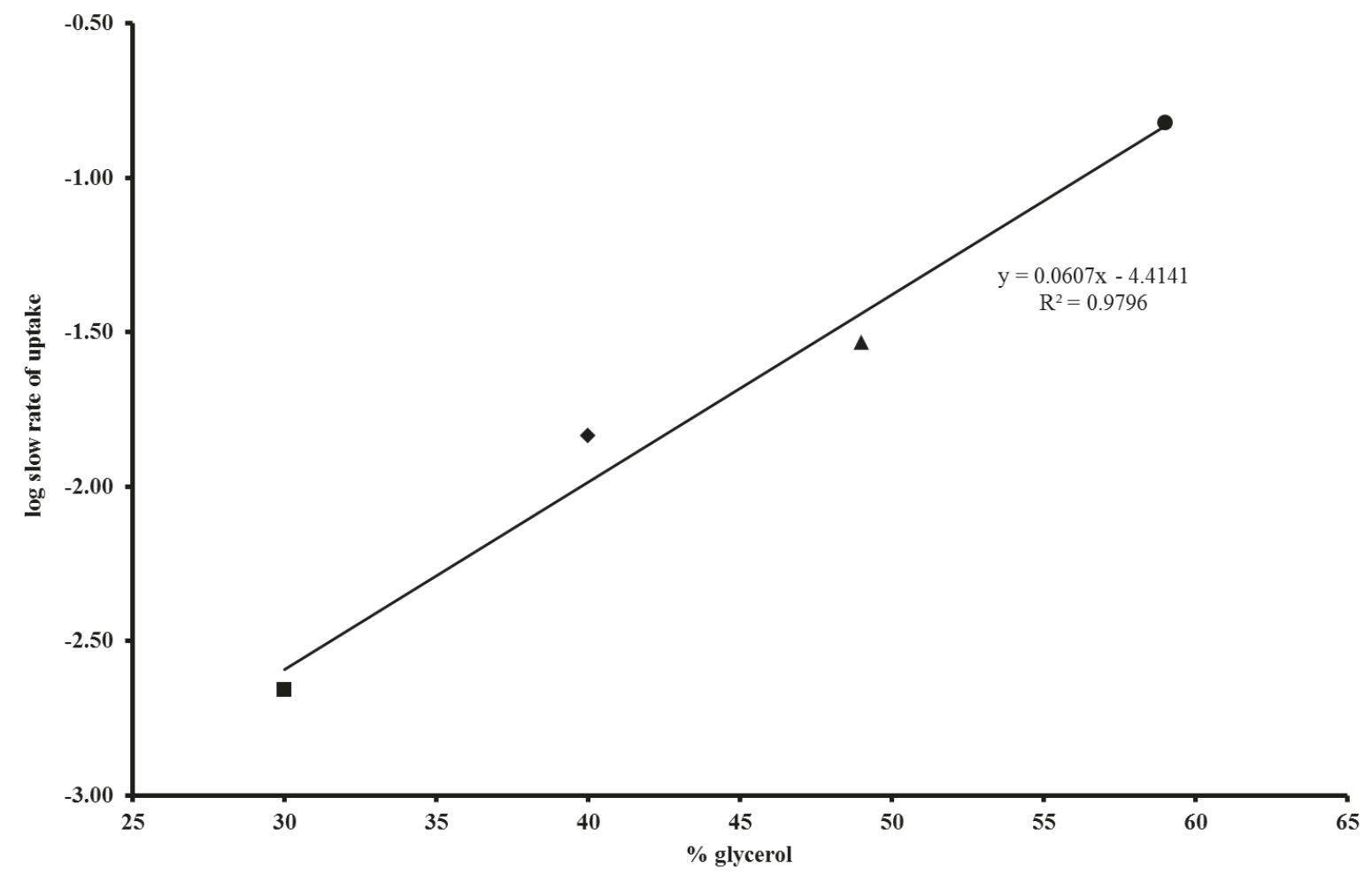

FIGURE 5 Relationship between the log of the falling solution density and the concentration of glycerol during the 'slow' stage of each impregnating step of a Bump-head Sunfish Mola alexandrini.

a measurably different colour after glycerol treatment (Table 4) and that the difference makes the specimen appear much more life-like and provides an improved specimen for exhibition.

At the end of the treatment, the sunfish specimen increased by $20 \mathrm{~kg}$, from an initial weight of $148 \mathrm{~kg}$ to a final weight of $168 \mathrm{~kg}$.

\section{DISCUSSION}

Previous experience of treating sharks with glycerol had indicted that the surface area to volume ratio was a significant determinant in the rates of uptake of glycerol (MacLeod and van Dam 2011). The sunfish had a surface area to volume ratio of $0.19 \mathrm{~cm}^{-1}$, which is similar to the large Megamouth Shark (0.23 $\mathrm{cm}^{-1}$; MacLeod 2015), so it was anticipated that both specimens should have similar rates of glycerol uptake. However, the initial rate of decrease of the density in $30 \%$ glycerol for the body of the sunfish was almost 14 times slower than the same solution used on the Megamouth Shark (Table 2).

The underlying cause for the slower rate of glycerol uptake in the sunfish is likely due to two main factors. Firstly, the sunfish has much more densely packed denticles compared to the larger amount of free space around each denticle in the Megamouth Shark (Figure 3 ). If the amount of free space is the major controlling factor, the sunfish should have taken 37 months, as the Megamouth Shark had 1.52 times the amount of free space compared with the sunfish. The critical role played by this is highlighted by the differential absorption rates of glycerol between areas that had a higher or lower concentration of denticles on the sunfish. The clavus region had a $23 \%$ higher absorption rate than average for the sunfish body due to fewer denticles in this articulated region of the fish, which covers approximately $10 \%$ of the surface of the sunfish. Secondly, the shark and the sunfish had different preservation histories prior to glycerol treatment. The Megamouth Shark was stored in ethanol for many years, which probably caused shrinkage and damage to cell membranes and consequently changes to the intercellular spaces, which might have created conditions to the skin surface and tissues allowing easier access of the glycerol solutions. The details of the mechanism may only be resolved by comparison of other marine specimens that have been fixed by formaldehyde and not treated with aqueous ethanol. We also note that the impregnation process is likely to be shorter than reported here, but due to many logistical reasons, increasing the solution concentration was usually delayed beyond when the density had reached equilibrium at each step. It should also be noted that the Megamouth Shark impregnation took place inside an exhibition gallery at the Western Australian Maritime Museum with a mean temperature of $21.8 \pm$ $1.4^{\circ} \mathrm{C}$ so this helped to overcome the oscillations that were observed with the fluctuating temperatures in the $40 \%$ sunfish solution.

Vastly improved flexibility and colour of the sunfish specimen was an important outcome for this exhibition specimen. Anecdotally, we also noted improvements to 
areas of 'freezer burn'. One methodological issue we encountered is the importance of carefully wiping the skin surface before doing chromameter measurements on specimens freshly removed from treatment solutions. Light reflects strongly off the wet surface and can cause erroneous readings.

\section{KINETICS OF GLYCEROL ABSORPTION INTO THE SUNFISH}

Both the initial rapid fall in density (Equation 3) and the slower rate (Equation 4) have the same dependence on glycerol concentration so it is likely that the same mechanism is controlling the uptake of glycerol, but there are two steps in the process. This makes intuitive sense, for the initial surge in the impregnation rate with each increased amount of glycerol added to the solution bath would provide additional driving forces to get the stabilising chemical into the specimen. The difference in the intercept values of Equations 3 and 4 (0.31) means that the slow rate has a starting point at half that of the rapid rate of decreasing the density of the impregnating solution. There was only a small difference between the rapid and slow rates of decrease for the initial $30 \%$ solution which is likely due to the osmotic pressure being insufficiently different to provide enough driving force for absorption. The first rapid decrease in density appears to be controlled by the osmotic pressure of the increased glycerol concentration. During this process large numbers of water molecules diffuse to the solution interface and then mix to 'lower' the solution concentration of glycerol. This is followed by a second step, which is a chemical absorption reaction as the glycerol migrates through the skin and releases more water into the impregnating solution. Studies on human tissue using $70 \%$ glycerol solutions have shown similar behaviour which included rapid removal of interstitial water through osmotic clearing followed by a slower response to outward diffusion of cleared cellular paths (Genina et al. 2006). It is possible that the initial rapid fall in density with each addition of glycerol may also be partly due to residual formaldehyde coming from the specimen. However, this is considered unlikely since the treatment of sea jellies with glycerol has shown that as formaldehyde enters glycerol solutions the density increases due to the increased hydrogen bonding of the aqueous glycerol solutions (MacLeod, unpublished data).

MacLeod (2015) demonstrated that weight changes in shark specimens, which were previously stored in $70 \%$ ethanol, were predictable and changes in solution density provided an accurate proxy to the rate of uptake of glycerol into the specimens. However, this assumption did not hold for the sunfish, for which an unlikely $162 \mathrm{~kg}$ mass increase was predicted from changes to solution density rather than the actual increase of $20 \mathrm{~kg}$. Thermodynamic studies on the interaction of glycerol with proteins in cells have shown that there are a complex set of reactions in 30\% aqueous glycerol with lysozyme and solvent regions near protein $\mathrm{O}$ - and $\mathrm{N}$-atoms favour the formation of multiple hydrogen bonds with glycerol (Vagenende et al. 2009). These interactions contribute positively to the preferential interaction coefficient $(15 \pm 4$ water molecules per glycerol molecule) due to the preferential solvation by glycerol molecules (Vagenende et al. 2009). The sunfish weight increase correlates with an average eight water molecules leaving the specimen per single glycerol molecule being bonded to the tissue. Some of the movement of water out of the sunfish is in response to the osmotic presssure of the impregnating solutions and the balance is due to the replacement of hydrogen bonded water in the tissue in response to the inward movement of the glycerol.

The calculated weight gain showed that $28 \%$ of the increase took place in the original $30 \%$ solution and $52 \%$ took place in the final $(59 \%)$ treatment solution. It appears that the initial uptake is due to the wetting of the skin by the glycerol with some absorption followed by small increases at $40 \%$ and $49 \%$. The final weight increase took place owing to a concentration gradient across the denticles that was sufficient to penetrate the specimen, despite the increased viscosity of the more concentrated $59 \%$ solution.

Although glycerol has been used as a preservation and storage solution for museum specimens for more than 100 years, little is known about the underlying chemical processes of this technique. It is clear that large specimens can be impregnated and give excellent improvements in specimen condition, flexibility and colour over traditional ethanol storage, as well as health and safety advantages. Specimens can be impregnated either directly after formalin fixation or after long term storage in ethanol, with similar chemical processes, but different migration kinetics. Furthermore, microscopic surface features of the specimen can affect the rate of glycerol uptake and should be considered during planning. While the treated specimen is in storage and awaiting relocation into an exhibition tank the solution density is being monitored every six months and it is unchanged.

\section{ACKNOWLEDGEMENTS}

Our thanks go to Sue Morrison and Mark Allen for assistance with the fixing and impregnation of the sunfish. The assistance of Michael Verrall at the CSIRO microscopy unit at the AARC for imaging and analysis of the sunfish skin and the assistance from Bruce Ford of Microfading Australia in surface area calculations is gratefully acknowledged. We thank Marianne Nyegaard for discussions and advice on Mola identification and biology. The manuscript was much improved by the insights of two reviewers. 


\section{REFERENCES}

Australian Government (2017). Standard for the uniform scheduling of medicines and poisons. No. 18. Theraputic Goods Administration, Australian Government Department of Heath. Canberra. October 2017. www. legislation.gov.au/Details/F2017L01285. Accessed: 12/06/2018.

Denbigh, K. (1964). The Principles of Chemical Equilibrium, with applications in chemistry and chemical engineering. Cambridge University Press: Cambridge.

Ford, B. (2011). Non-destructive microfade testing at the National Museum of Australia. AICCM Bulletin 32: 54-64.

Fraser-Brunner, A. (1951). The ocean sunfishes (Family Molidae). Bulletin of the British Museum (Natural History) Zoology 1: 87-121.

Genina, E.A., Korobko, A.A., Bashkatov, A.N., Tuchin, V.V., Yaroslavsky, I.V. and Altshuler, G.B. (2006). Investigation of skin water loss and glycerol delivery through stratum corneum. Proceedings of SPIE 6535: 1605-7422.

Glycerine Producers Association (1963). Physical properties of glycerine and its solutions. Glycerine Producers Association: New York.

Graham, D. (1953). The Characterization of Physical Absorption Systems. I. The Equilibrium Function and Standard Free Energy of Absorption. Journal of Physical Chemistry 57: 665-669.

Graves, D.J. (2004). A comparative study of consolidants for waterlogged wood: polyethylene glycol, sucrose, and silicone oil. Scottish Society for Conservation and Restoration Journal 15: 13-17.

Human, B.A., Morrison, S.M. and MacLeod, I.D. (2012). Is the Megamouth Shark susceptible to mega-distortion? Investigating the effects of twenty-two years of fixation and preservation on a large specimen of Megachasma pelagios (Chondrichthyes: Megachasmidae). Records of the Western Australian Museum 27: 7-20. doi: 10.18195/ issn.0312-3162.27(1).2012.007-020

Hutchins, J.B. (2001). Molidae. In: FAO species identification guide for fishery purposes. The living marine resources of the Western Central Pacific. K.E. Carpenter and V.H. Niem (Eds.). Food and Agriculture Organization of the United Nations: Rome. pp. 3966-3968.

Kim, K.-H., Jahan, S.A. and Lee, J.-T. (2011). Exposure to Formaldehyde and Its Potential Human Health Hazards. Journal of Environmental Science and Health, Part C 29: 277-299.
MacLeod, I.D. (2008). Washing formaldehyde from fixed spirit specimens: a mechanism for the preservation of Megamouth III. Australian Institute for the Conservation of Cultural Materials Bulletin 31: 36-43.

MacLeod, I.D. (2015). Conservation of a museum megamouth shark specimen by changing its preservative from aqueous ethanol to aqueous glycerol. Collections Forum 29: 73-89.

MacLeod, I.D. and Gilroy, D.R. (1989). Colour measurement of treated and air-dried wood. Proceedings of the ICOM Conservation Working Groups on Wet Organic Archaeological Materials and Metals, Western Australian Museum.

MacLeod, I.D. and van Dam, A.J. (2011). A migration mechanism for transfer of sharks from ethanol to aqueous glycerol solutions. International Council of Museums-Committee for Conservation Triennial Meeting. Lisbon: $1-8$.

Nyegaard, M., Sawai, E., Gemmell, N., Gillum, J., Loneragan, N.R., Yamanoue, Y. and Stewart, A.L. (2018). Hiding in broad daylight: molecular and morphological data reveal a new ocean sunfish species (Tetraodontiformes: Molidae) that has eluded recognition. Zoological Journal of the Linnean Society 182: 631-658.

Pope, E.C., Hays, G.C., Thys, T.M., Doyle, T.K., Sims, D.W., Queiroz, N., Hobson, V.J., Kubicek, L. and Houghton, J.D.R. (2010). The biology and ecology of the ocean sunfish Mola mola: a review of current knowledge and future research perspectives. Reviews in Fish Biology and Fisheries 20: 471-487.

Ranzani, C. (1839). Dispositio familiae Molarum in genera et in species. Novi Commentarii Academiae Scientiarum Instituti Bononiensis 3: 63-82, Pl. 66 + table.

Vagenende, V., Yap, M.G.S. and Trout, B.L. (2009). Molecular Anatomy of Preferential Interaction Coefficients by Elucidating Protein Solvation in Mixed Solvents: Methodology and Application for Lysozyme in Aqueous Glycerol. Journal of Physical Chemistry B 113: 1174311753.

Whitley, G.P. (1933). Sunfishes. Victorian Naturalist 49: 207-213.

Wolf, A.V., Brown, M.G. and Prentiss, P.G. (1974). Concentrative properties of aqueous solutions: conversion tables. In: Handbook of Chemistry and Physics, A reference book of Chemical and Physical Data. CRC Press: Cleveland, Ohio. pp. D205.

MANUSCRIPT RECEIVED 11 JULY 2018; ACCEPTED 27 NOVEMBER 2018. 